\title{
DISPENSA COLETIVA E NEGOCIAÇÃO SINDICAL
}

\author{
MASS DISMISSAL AND UNION NEGOTIATION
}

Estêvão Mallet ${ }^{*}$

\begin{abstract}
Resumo:
$\mathrm{O}$ artigo envolve o exame da necessidade ou não de negociação sindical para a realização de dispensa coletiva. Parte da consideração dos fundamentos invocados pelas decisões para justificar a imposição da exigência conclui que, no sistema jurídico brasileiro, ela não se justifica.

Palavras-chave: Dispensa coletiva. Negociação sindical. Princípios constitucionais. Neopositivismo.
\end{abstract}

\begin{abstract}
:
The paper examines whether union negotiation is necessary for a mass dismissal of workers. It deviates from the fundamentals invoked through rulings that justify the imposition of negotiation and concludes that such demand is not justified by the Brazilian legal system.
\end{abstract}

Keywords: Mass dismissal. Union negotiation. Constitutional principles. Neopositivism.

\section{Introdução}

A grave crise econômica enfrentada pelo país nos últimos tempos provocou o crescimento, de maneira súbita e sensível, do desemprego, cujos índices teriam praticamente dobrado em quase dois anos, atingindo o "maior resultado da série histórica da Pesquisa Nacional por Amostra de Domicílios Contínua". ${ }^{1}$ São frequentes as notícias sobre dispensas de grande número de trabalhadores de uma mesma empresa, realizadas simultaneamente ou em curto espaço de tempo. ${ }^{2}$ Nesse cenário, o problema da

Professor de Direito do Trabalho da Faculdade de Direito da Universidade de São Paulo, Doutor e LivreDocente em Direito e advogado.

1 AMORIM, Daniela. Desemprego sobe e renda volta ao nível de 2013. O Estado de S. Paulo, São Paulo, 30 jul. 2016. Caderno Economia, p. B6. Se em dezembro de 2013 o percentual de desemprego estava à volta de $6 \%$, já passou $11 \%$ no ano em curso, chegando, em abril, a 11,2\%, segundo dados da PNAD. Disponível em: <http://br.advfn.com/indicadores/pnad>. Acesso em: 10 ago. 2016.

2 A Confederação Nacional do Comércio divulgou ter ocorrido o fechamento de quase setenta mil lojas entre janeiro e junho do corrente ano. Cf. a notícia (FERNANDES, Adriana; DE CHIARA, Márcia. Varejo fechou 375 lojas por dia este ano. O Estado de S. Paulo, São Paulo, 3 ago. 2016. Caderno Economia, p. B6). Dois dias depois, o mesmo jornal traz notícia sobre indústria montadora de veículos que pretende dispensar 1.800 empregados, em decorrência da redução das vendas (SILVA, Cleide; ROCHA, André Ítalo. Mercedes-Benz anuncia demissões no $\mathrm{ABC}$ e metalúrgicos param produção. O Estado de S. Paulo, São Paulo, 5 ago. 2016. Caderno Economia, p. B10). 
necessidade ou não de prévia negociação sindical para a realização de dispensa coletiva, que já provocou grande debate na jurisprudência e ainda permanece pendente de solução, adquire renovada atualidade, a justificar que se retome o seu exame.

\section{Os antecedentes}

Ao que parece, foi a partir de um julgamento do Tribunal do Trabalho da $2^{\text {a }}$ Região, proferido em dezembro de $2008,{ }^{3}$ que se passou a considerar necessária prévia negociação sindical para a dispensa coletiva de empregados. Não há indicação de outro precedente mais antigo do gênero, nem se tem notícia clara de formulação dessa mesma exigência em data mais recuada.

A matéria adquiriu mais notoriedade, todavia, com o subsequente pronunciamento do Tribunal do Trabalho da $15^{\mathrm{a}}$ Região, que reafirmou a proposição, ${ }^{4}$ inclusive por se ter encerrado por acordo o processo anterior, do Tribunal do Trabalho da $2^{\mathrm{a}}$ Região. Foi no âmbito do segundo processo, do Tribunal do Trabalho da $15^{\mathrm{a}}$ Região que o Tribunal Superior do Trabalho, ao apreciar recursos das partes, firmou, por maioria mínima (cinco votos contra quatro), a tese de que "a negociação coletiva é imprescindível para a dispensa em massa de trabalhadores", 5 tese que tem sido aplicada em sucessivos julgamentos desde então. ${ }^{6}$

Adecisão do Tribunal Superior do Trabalho, porém, veio a ser impugnada por recurso extraordinário. Inicialmente indeferido o seu processamento, deu-se o provimento monocrático do agravo regimental que se seguiu ao agravo de instrumento, ${ }^{7}$ reconhecendo o Plenário, contra um voto vencido, a repercussão geral da matéria. ${ }^{8}$ Atualmente aguardase o julgamento do recurso extraordinário, após parecer do Ministério Público, de abril do corrente ano, pelo seu desprovimento.

TRT - 2a Reg., SDC, Proc. N. 20281200800002001, Rel. Ivani Contini Bramante, Ac. n. 00002/2009-0, julg. em 22.12.2008.

4 TRT - 15 Reg., SDC, Proc. n. 00309-2009-000-15-00-4 DC, Rel. José Antonio Pancotti, Ac. 00333/09 in DEJT de 30.3.2009.

5 TST - SDC, Proc. n. 309/2009-000-15-00.4, Rel. Min. Mauricio Godinho Delgado, julg. em 10.8.2009.

6 Por exemplo, como mera ilustração: TST - SDC, Proc. RO n. 173-02.2011.5.15.0000, Rel. Min. Mauricio Godinho Delgado, julg. em 13.8.2012 in DEJT de 31.8.2012; TST - SDC, Proc. n. 100019161.2014.5.02.0000, Rel. Min. Kátia Magalhães Arruda, julg. em 11.4.2016 in DEJT de 29.4.2016 e TST - SDC, Proc. n. 6155-89.2014.5.15.0000, Rel. Min. Maria de Assis Calsing, julg. em 22.2.2016 in DEJT de 26.2.2016.

7 STF - ARE n. 647.651, Rel. Min. Marco Aurélio, decisão de 24.3.2012.

8 Ac. de 22.3.2013. 


\title{
3. Fundamentos da tese
}

A despeito das naturais e expectáveis diferenças de fundamentação, um traço comum entre todos os três acórdãos da Justiça do Trabalho mencionados (os dois dos Tribunais Regionais e o terceiro do Tribunal Superior do Trabalho) é o largo emprego que neles se encontra, ao longo de toda a argumentação, de princípios constitucionais. Desde o princípio da dignidade da pessoa humana - princípio de baixa densidade normativa, de fácil utilização, portanto, nos mais variados contextos -, citado em todos, até outros, com conexão muito menos óbvia e mais distante do problema, como o princípio da solução pacífica das controvérsias, referido no preâmbulo da Constituição e que aparece apenas na decisão do Tribunal da $2^{\mathrm{a}}$ Região, invoca-se sempre longo rol de princípios para considerar ilícita a dispensa coletiva não precedida de negociação sindical. A síntese paradigmática do raciocínio está no acórdão do Tribunal Superior do Trabalho, na seguinte passagem:

\begin{abstract}
Regras e princípios constitucionais que determinam o respeito à dignidade da pessoa humana (art. $\left.1^{\circ}, \mathrm{III}, \mathrm{CF}\right)$, a valorização do trabalho e especialmente do emprego (arts. $1^{\circ}, \mathrm{IV}, 6^{\circ}$ e $170, \mathrm{VIII}, \mathrm{CF}$ ), a submissão da propriedade à sua função socioambiental (arts. $5^{\circ}$, XXIII e 170, III, CF) e a intervenção sindical nas questões coletivas trabalhistas (art. $8^{\circ}$, III e VI, CF), tudo impõe que se reconheça a distinção normativa entre as dispensas meramente tópicas e individuais e as dispensas massivas, coletivas, as quais são social, econômica, familiar e comunitariamente impactantes. Nesta linha, é inválida a dispensa coletiva enquanto não negociada com o sindicato de trabalhadores, seja espontaneamente, seja no plano do processo judicial coletivo. ${ }^{9}$
\end{abstract}

Citam-se, ainda, outros fundamentos para a afirmação da necessidade de negociação prévia em dispensa coletiva, como, em particular, a) a lacuna existente na ordem jurídica brasileira sobre a matéria, a reclamar e justificar o seu preenchimento pelo julgador, b) a impossibilidade de admitir-se o exercício abusivo do direito de dispensar empregados, como consta da decisão do Tribunal Superior do Trabalho, bem como, por fim, c) a existência de normas internacionais, especialmente da Organização Internacional do Trabalho (Convenções OIT ns. 11, 87, 98, 135, 141 e 151), impeditivas de dispensa coletiva não negociada com os sindicatos.

TST - SDC, Proc. n. 309/2009-000-15-00.4, Rel. Min. Mauricio Godinho Delgado, julg. em 10.8.2009, fl. 30 . 
4. Os princípios constitucionais invocados para impor a negociação sindical prévia na dispensa coletiva

A larga utilização de princípios constitucionais para afirmar a ilegalidade de dispensas coletivas não negociadas é um sintoma bem indicativo, em um domínio particular - o Direito do Trabalho -, da transformação mais ampla experimentada pela reflexão jurídica brasileira mais recente, em linha com o que se vê nos sistemas romanogermânicos em geral.

De um maior apego ao positivismo, marcante no raciocínio jurídico até o advento da Constituição de 1988, passou-se gradualmente para o campo do pós-positivismo ou neopositivismo, com favorecimento da argumentação baseada em princípios. ${ }^{10} \mathrm{Um}$ autor português, por exemplo, escreve que "nunca antes, como hoje, teve tamanha intensidade a ideia de um Direito fundado - a partir de cima - em 'princípios'..."."1

Até no direito posto o fenômeno se manifesta de forma nítida. Para ficar em um exemplo eloquente e atual, não deixa de ser significativo o fato de o Código de Processo Civil de 2016 mencionar quatorze princípios, ${ }^{12}$ enquanto o Código anterior, de 1973, referia-se, quando muito, a três. ${ }^{13} \mathrm{O}$ mesmo se vê em vários outros diplomas, ${ }^{14}$

10 A propósito, cf. ÁVILA, Humberto. "Neoconstitucionalismo": entre a "ciência do direito" e o direito da ciência”. Revista Eletrônica de Direito do Estado (REDE), Salvador, n. 17, p. 1-19, jan./mar. 2009. p. 2, RAMOS, Elival da Silva. Parâmetros dogmáticos do ativismo judicial em matéria constitucional. 2009. Tese (Professor Titular) - Faculdade de Direito, Universidade de São Paulo, São Paulo, 2009. p. 241/242, bem como, no Direito Comparado, o texto já citado de António Cortês, em que se lê: "Por detrás de todas estas novas realidades metódicas o que se esconde é, no fundo, uma nova filosofia que confere um peso acrescido aos princípios de Direito - enquanto parâmetros normativos e enquanto referenciais ideais - sobre as meras normas em sentido técnico dotadas de previsão e estatuição." (Jurisprudência dos princípios Ensaio sobre os fundamentos da decisão jurisdicional cit., p. 79).

11 CORTÊS, António. Jurisprudência dos princípios: ensaio sobre os fundamentos da decisão jurisdicional. Lisboa: Universidade Católica Editora, 2010. p. 171.

12 Cf. arts. 41, parágrafo único, $166,167, \S 2^{\circ}, 322, \S 2^{\circ}, 489, \S 2^{\circ}, 685$, parágrafo único, e 927 , $\S 4^{\circ}$, com as menções aos princípios da "reciprocidade de tratamento", "independência", "imparcialidade", "autonomia da vontade", "confidencialidade", "oralidade", "informalidade", "decisão informada", "igualdade dentro da mesma área de atuação profissional", "boa-fé”, "duração razoável do processo", "segurança jurídica", "proteção da confiança" e "isonomia".

13 Art. 548, com a alusão aos princípios da "publicidade... alternatividade e... sorteio". Não se considera a referência, no art. 126, aos princípios gerais do direito, por se tratar de mero critério de integração do ordenamento, não de princípio a ser observado na aplicação da legislação processual. Tampouco se leva em conta o art. 588, caput, em que a alusão aos "princípios" regentes da execução provisória resulta de clara atecnia, já que não se trata de princípios, mas de verdadeiras regras, como se explicitou com a redação dada ao preceito pela Lei n. 10.444 .

14 O legislador tem abusado da menção a princípios, a ponto de ser hoje corrente iniciar-se o texto legislativo por um rol deles. De muitos não se tinha notícia até o momento da primeira referência normativa. Como mera ilustração e sem o propósito de ser exaustivo, citam-se a Lei n. 9.394, em que se menciona, por exemplo, um suposto princípio da "garantia de padrão de qualidade" do ensino (art. $3^{\circ}$, inciso IX, repetição, aliás, do art. 206, inciso VII, da Constituição), a Lei n. 12.965, sobre a internet, com a referência a outro princípio inusitado, o da "preservação da estabilidade, segurança e funcionalidade da rede" (art. $3^{\circ}$, inciso 
inclusive na própria Constituição, na qual figuram mais de três dezenas de princípios, alguns muito surpreendentes, como, por exemplo, um princípio da exceção - o que parece ser um contrassenso -, a saber, o princípio da excepcionalidade da medida privativa da liberdade de criança, adolescente e jovem. ${ }^{15}$

De qualquer sorte, os princípios invocados no caso das dispensas coletivas não são suficientes para justificar a conclusão que se pretende alcançar. Aliás, é difícil compreender como tais princípios (dignidade da pessoa humana, valorização do trabalho e especialmente do emprego, submissão da propriedade à sua função socioambiental), com a abrangência que apresentam, possam ser utilizados para afirmar a proibição, sem negociação prévia, apenas de dispensas coletivas, não de dispensas individuais. Nos termos do art. $8^{\circ}$, III, da Constituição, cabe ao sindicato a defesa não apenas dos direitos e interesses coletivos dos empregados como, também, dos individuais. E a dignidade da pessoa humana, em particular, não tem índole meramente coletiva. Antes ao contrário, está muito mais associada ao indivíduo, à pessoa humana, do que aos grupos. Logo, fosse bom o argumento, também as dispensas individuais ou não coletivas teriam de ser precedidas de negociação, o que ainda não se vê proposto.

O que se nota, na situação concreta, é que os princípios, especialmente o da dignidade da pessoa humana, são utilizados de maneira "meramente retórica", ${ }^{16}$ aproveitando-se de sua maior indeterminabilidade para os instrumentalizar "em favor de concepções particulares não consensualmente partilhadas que se procuram impor coercitivamente". ${ }^{17}$ Para além dos problemas gerais que isso ocasiona, com soluções nem sempre corretas, há uma patente "degradação normativa" de todos eles - uma "desvalorização e desqualificação"18 -, ao lado de uma latente ameaça à "estabilidade dos limites funcionais do poder judicial, já que uma eventual facilidade do recurso ao princípio enquanto fundamento de controle das opções do legislador democrático estimula um activismo judicial não constitucionalmente sustentado". ${ }^{19}$

V), além da Lei Complementar n. 95, que cria o princípio segundo o qual "o mesmo assunto não poderá ser disciplinado por mais de uma lei, exceto quando a subseqüente se destine a complementar lei considerada básica, vinculando-se a esta por remissão expressa" (art. $7^{\circ}$, inciso IV).

15 Art. $227, \S 3^{\circ}$, inciso V. Transformar a exceção em princípio é fazer com que ela deixe de ser exceção.

16 NOVAIS, Jorge Reis. A dignidade da pessoa humana. Dignidade e direitos fundamentais. Coimbra: Almedina, 2015. v. 1. p. 13.

17 NOVAIS, Jorge Reis. A dignidade da pessoa humana ... cit., v. 1, p. 122.

18 NOVAIS, Jorge Reis. A dignidade da pessoa humana ... cit., v. 1, p. 82.

19 NOVAIS, Jorge Reis. A dignidade da pessoa humana. Dignidade e inconstitucionalidade. Coimbra: Almedina, 2016. v. 2. p. 74. O mesmo autor, em outra passagem, anota: "um menor rigor jurídico na alegação de violação da dignidade da pessoa humana, atendendo aos efeitos destrutivos que produz quando é bem sucedida, é naturalmente problemática. Veja-se, nesse sentido, a utilização muito comum do princípio da dignidade da pessoa humana por parte dos tribunais brasileiros..." (NOVAIS, Jorge Reis. A dignidade da pessoa humana. Dignidade e direitos fundamentais. Coimbra: Almedina, 2015. v. 1. p. 22). 
É uma certa repetição do que se viu em outros lugares e em outros tempos. Nos Estados Unidos da América, especialmente na altura da chamada Corte Warren, talvez no seu último expressivo pronunciamento, tomado já após o afastamento do Chief Justice que tanto a marcou, até o direito à intimidade, não previsto na Constituição, mas deduzido do due process of law, serviu para afirmar-se a inconstitucionalidade da criminalização do aborto. ${ }^{20}$ Com o princípio da dignidade da pessoa humana do direito brasileiro pode-se, mais facilmente e com menos necessidade de elaboração teórica ou esforço argumentativo, chegar a qualquer resultado que se queira. Posições opostas e antagônicas podem ser igualmente defendidas com pretenso amparo na Constituição. ${ }^{21}$

O problema é que tamanha abertura tem também os seus inconvenientes. Para voltar à experiência norte-americana, o mesmo princípio do due process of law, que permitiu enunciar o direito ao aborto, antes havia se prestado à declaração de inconstitucionalidade de lei estadual limitadora da jornada de trabalho em padarias. ${ }^{22} \mathrm{O}$ ponto fraco, pois, não é tanto - ou não é apenas - o resultado, mas, sobretudo, a forma como se chega a ele.

Da participação obrigatória dos sindicatos na negociação coletiva, que a Constituição efetivamente impõe (art. $8^{\circ}, \mathrm{VI}$ ), não se tira, de nenhuma forma, a exigência

20 Na súmula da decisão proferida em Roe v. Wade (410 U.S. 113) lê-se: "3.State criminal abortion laws, like those involved here, that except from criminality only a life-saving procedure on the mother's behalf without regard to the stage of her pregnancy and other interests involved violate the Due Process Clause of the Fourteenth Amendment, which protects against state action the right to privacy, including a woman's qualified right to terminate her pregnancy".

21 O uso dilatado - talvez seja mais apropriado falar em abuso - do princípio da dignidade da pessoa humana pode servir, por exemplo, tanto para afirmar-se a completa proibição de realização de pesquisas científicas com embriões humanos como para, ao contrário, afirmar a sua perfeita licitude. A hipótese nem de longe é acadêmica. Jorge Reis Novais lembra, de maneira expressiva, que em dois sistemas em que se respeita o mencionado princípio (Reino Unido e Alemanha), a solução dada ao problema é oposta. Cf. NOVAIS, Jorge Reis. A dignidade da pessoa humana. Dignidade e direitos fundamentais. Coimbra: Almedina, 2015. v. 1. p. 23, nota 8 . Outro exemplo, lembrado pelo mesmo autor, envolve o célebre caso do lançamento do anão. Empresa de espetáculos promovia exibição consistente no lançamento de anão à distância. Teve proibida a atividade por decisão do Conseil d'État francês (Commune de Morsang-sur-Orge, Processo n. 136.727, decisão de 27.10.1995), sob fundamento de "atteinte à la dignité de la personne humaine". O ponto curioso é que o princípio da dignidade da pessoa humana foi invocado, no processo administrativo, tanto pelo Estado como pelo anão, "que imputava ao Estado a violação da sua dignidade, na medida em que, em nome de concepções morais, de ordem pública ou de dignidade que ele não partilhava e que supostamente se destinavam a protegê-lo, os poderes públicos o privaram do único emprego ao seu alcance e impediram-no de viver uma vida honesta, em autodeterminação e liberdade individual." (NOVAIS, Jorge Reis. A dignidade da pessoa humana. Dignidade e direitos fundamentais. Coimbra: Almedina, 2015. v. 1. p. 111).

22 Trata-se da decisão tomada em Lochner v. New York (198 U.S. 45), em que se afirma: "The statute necessarily interferes with the right of contract between the employer and employees, concerning the number of hours in which the latter may labor in the bakery of the employer. The general right to make a contract in relation to his business is part of the liberty of the individual protected by the 14th Amendment of the Federal Constitution". Embora o pronunciamento mereça a mais severa crítica, ela se torna mais falha quando parte de quem favorece incontida aplicação de princípios constitucionais. 
de entendimento antes das dispensas coletivas. A participação do sindicato supõe a necessidade da negociação. Ora, a dispensa, como ato caracterizado, segundo o direito posto, como receptício unilateral, seja feita individualmente ou de forma coletiva, não depende de negociação. Depende apenas de comunicação. O argumento utilizado adota como premissa o que pretende provar (petitio principii).

Não deixa de causar ainda alguma perplexidade o uso que se faz de certos princípios ao lado do silêncio em torno da aplicação de normas com conteúdo preceptivo bem mais forte e claro. Se a dignidade da pessoa humana serve para impedir dispensas coletivas, por que não a aplicar, conjugada inclusive com o explícito comando do art. $7^{\mathrm{o}}$, inciso VI, da Constituição, e, eventualmente, com outros princípios que haveria para mencionar, a fim de elevar o valor do salário-mínimo, tendo-se presente a notória insuficiência da cifra estabelecida por lei? O que há no princípio que permite um resultado e não impõe o outro?

\section{Inexistência de lacuna}

Os demais fundamentos não diretamente principiológicos citados pelas decisões (lacuna sobre a matéria, a reclamar preenchimento pelo julgador, e impossibilidade de admitir-se o exercício abusivo do direito de dispensar empregados) também apresentam fragilidades significativas.

É questionável a ideia de existir lacuna no sistema jurídico brasileiro sobre a dispensa coletiva. A CLT refere-se sim a uma hipótese, deveras paradigmática, de dispensa coletiva. Trata-se da extinção da empresa, caso tão típico de dispensa coletiva que o legislador mexicano mencionou-o de forma expressa e em primeiro lugar, ao tratar das dispensas coletivas. A Ley Federal del Trabajo, no art. 433, sob a rubrica de Terminación colectiva de las relaciones de trabajo, estabelece: "La terminación de las relaciones de trabajo como consecuencia del cierre de las empresas o establecimientos o de la reducción definitiva de sus trabajos, se sujetará a las disposiciones de los artículos siguientes". Na Itália, igualmente, a doutrina sublinha que no "ambito del licenziamento collettivo per riduzione di personale viene compresso anche quello intimato dall'imprenditore che intenda cessare totalmente e definitivamente l'attività". ${ }^{23}$ Pois bem, os arts. 497 e 502 da CLT cuidam da extinção da empresa e não mencionam necessidade de negociação coletiva. O art. 498, por sua vez, disciplina o "fechamento do estabelecimento, filial ou

23 GHERA, Edoardo; GARILlI, Alessandro; GAROFALO, Domenico. Diritto del lavoro. Torino: G. Giappichelli, 2013. p. 578. A doutrina está a fazer referência ao articolo 24, comma 2, da Legge n. 223/1991: "Le disposizioni richiamate nel comma 1 si applicano anche quando le imprese di cui al medesimo comma intendano cessare l'attività". 
agência" - outra hipótese que envolve dispensa coletiva - e tampouco cogita de negociação coletiva. Essas disposições, que tratam de casos relacionados necessariamente com dispensa coletiva, ${ }^{24}$ sem mencionar prévia negociação sindical, mostram que o legislador não quis mesmo exigir a formalidade. Pode-se censurar o legislador e considerar a solução incorreta. Mas não se pode dizê-lo omisso.

A própria Constituição, no art. 10 do Ato das Disposições Constitucionais Transitórias, limitou a proteção estabelecida pelo art. $7^{\circ}$, inciso I, à elevação da multa em caso de dispensa imotivada e à proibição de certas dispensas. Não cogitou de negociação sindical prévia em dispensas coletivas. Lançar mão de princípios para contrariar regra positivada na Constituição afigura-se excessivo. Como anota a doutrina, "num conflito, efetivo ou aparente, entre uma regra constitucional e um princípio, deve vencer a regra". ${ }^{25}$

Não se deve confundir a não regulamentação de situação especial, de certa forma, com lacuna verdadeira. Nem sempre quando o legislador deixa de estabelecer disciplina própria para um caso particular - ou novo - há uma omissão. Muitas vezes há, tão-somente, sujeição desse caso particular à regra geral prevista. ${ }^{26}$ Há, no máximo, "lacune improprement dite" ${ }^{27}$ ou, se se preferir, lacuna de iure condendo, não de iure condito. ${ }^{28}$ É o que se dá com a dispensa coletiva no direito brasileiro, a qual fica sujeita às regras previstas para a dispensa em geral, individual ou coletiva.

Se lacuna houvesse na regulação da dispensa coletiva, não seria ela preenchida com a imposição, pelo julgador, de obrigação de negociação prévia. $\mathrm{O}$ sistema jurídico brasileiro não incorporou a diretriz do direito suíço, em que, na falta de disposição legal, o juiz decide "selon les règles qu'il établirait s'il avait à faire acte de législateur". ${ }^{29} \mathrm{~A}$ integração se faz de outro modo e envolve a aplicação sucessiva dos critérios preconizados pelo art. $8^{\circ}$ da CLT. ${ }^{30}$ Ora, na jurisprudência - primeiro critério a que

24 Cf. a decisão proferida pelo Tribunal Superior do Trabalho, no Proc. RO n. 6-61.2011.5.05.0000 (SDC), Rel. Min. Walmir Oliveira da Costa, julg. em 11.12.2012 in DEJT de 22.2.2013, em que se define como coletiva a dispensa pelo fato de "a empresa suscitada (ter) encerr(ado) suas atividades no município de Aratu-BA, procedendo à dispensa de todos os empregados dessa unidade industrial...".

25 ÁVILA, Humberto. "Neoconstitucionalismo": entre a "ciência do direito" e o direito da ciência" ... cit., p. 5.

26 Cf. TENÓRIO, Oscar Acioli. Lei de introdução ao código civil brasileiro: decreto-lei n. 4.657, de 4 de setembro de 1942. Rio de Janeiro: Borsoi, 1955. n. 166. p. 107/108.

27 SCYBOZ, Georges; GILliÉRON, Pierre-Robert; SCYBOZ, Pierre. Code civil suisse et Code des obligations: annotés. 7e éd. mise à jour. Lausanne: Payot, 2004. p. 4.

28 Cf. BOBBIO, Norberto. Teoria dell'ordinamento giuridico. Torino: G. Giappichelli, 1960. p. 158/159.

29 Art. $1^{\circ}$, n. 2, do Code Civil suisse. A doutrina anota que nem mesmo diante da regra transcrita ao juiz é dado criar livremente o direito (jus dare). Cabe-lhe, no fundo, buscar a solução emergente do sistema (jus dire). Cf., para algumas poucas notas sobre a matéria, DU PASQUIER, Claude. Introduction à la théorie générale et à la philosophie du droit. 3. ed., mise a jour et augm. Neuchatel: Delachaux \& Niestlé, 1948. n. 216, p. 201.

30 "As autoridades administrativas e a Justiça do Trabalho, na falta de disposições legais ou contratuais, decidirão, conforme o caso, pela jurisprudência, por analogia, por eqüidade e outros princípios e normas 
se refere o legislador - não havia, antes das decisões mencionadas há pouco, exigência de negociação sindical para dispensa coletiva. A analogia - segundo critério - leva a adotarse o regramento pertinente à dispensa comum, o que há de mais próximo à dispensa coletiva, ou seja, desnecessidade de negociação prévia. Os princípios - terceiro critério - não oferecem indicativo de solução, já que, como visto, não se ocupam do assunto. Os usos e costumes - quarto critério - não envolviam, antes da mudança da jurisprudência, a prática de negociação. Eram pouco significativos e isolados os casos em que isso ocorria. Predominava a ausência de negociação, sendo certo que o elemento material do costume é também a "generalidade", ${ }^{31}$ o que supõe prática "largement répandu dans le millieu social, la profession, la localité, observé par la plupart des gens". ${ }^{32}$ O Direito Comparado, por fim, além de ser, por razões óbvias, pouco utilizado como critério de integração de lacunas na legislação trabalhista, ${ }^{33}$ não oferece indicação segura de parâmetro, dada a multiplicidade de definições de dispensa coletiva que nele se encontra, como em breve será melhor exposto. Quer dizer, considerado lacunoso o ordenamento nacional, nem assim passa a ser necessária a negociação sindical para a dispensa coletiva de empregados.

\section{Impossibilidade de exercício abusivo do direito de dispensar empregados}

É correta a tese contrária ao exercício abusivo do direito de dispensar empregados. Aliás, Josserand, quando escreveu sobre o abuso de direito em geral, ainda na primeira metade do Século passado, teve em mente que "le droit qui appartient à chacune des parties, dans le louage de services à durée indéterminée, de rompre unilatéralement le contrat, est susceptible d'abus". ${ }^{34}$ Tempos depois, Camerlynk advertiu ser o contrato de trabalho "un terrain de choix" de práticas abusivas, por conta "de l'inégalité des contractants en présence". 35

Mas a ilicitude do exercício abusivo do direito existe tanto no plano coletivo como no individual. Em outros termos, é ilícita não apenas a dispensa coletiva abusiva

gerais de direito, principalmente do direito do trabalho, e, ainda, de acordo com os usos e costumes, o direito comparado, mas sempre de maneira que nenhum interesse de classe ou particular prevaleça sobre o interesse público".

31 ESPINOLA, Eduardo; ESPINOLA FILHO, Eduardo. A lei de introdução ao código civil brasileiro. Rio de Janeiro: Freitas Bastos, 1943. v. 1. n. 50, p. 115.

32 LA GRESSAYE, Jean Brethe de; LABORDE-LACOSTE, Marcel. Introduction générale a l'étude du droit. Paris: Sirey, 1947. n. 306, p. 277.

33 Diferenças econômicas, sociais e histórias tornam muito difícil a eficiente utilização do Direito Comparado para a integração das lacunas da legislação trabalhista.

34 JOSSERAND, Louis. De l'esprit des droits et de leur relativité. Théorie dite de l'abus des droits. Paris: Dalloz, 1939. n. 141, p. 193.

35 CAMERLYNCK, G. H., Traité de droit du travail. Contrat de travail. Paris: Dalloz, 1968. 195, p. 350. 
como a dispensa individual abusiva. Bem se pode dizer, de maneira mais acertada, que é ilícita a dispensa abusiva tout court.

De todo modo, a proibição de exercício abusivo do direito de dispensar não se traduz em exigência de prévia negociação sindical. Implica, tão somente, a ilicitude de dispensa que se tenha por abusiva.

\title{
7. Normas internacionais
}

A decisão do Tribunal Superior do Trabalho refere também convenções da Organização Internacional do Trabalho, de n. 11, 87, 98, 135, 141 e 151, como justificativa para a necessidade de prévia negociação sindical para a dispensa coletiva de empregados, nos seguintes termos:

\begin{abstract}
A ordem constitucional e infraconstitucional democrática brasileira, desde a Constituição de 1988 e diplomas internacionais ratificados (Convenções OIT n. 11, 87, 98, 135, 141 e 151, ilustrativamente), não permite o manejo meramente unilateral e potestativista das dispensas trabalhistas coletivas, por (s)e tratar de ato/fato coletivo, inerente ao Direito Coletivo do Trabalho, e não Direito Individual, exigindo, por conseqüência, a participação do(s) respectivo(s) sindicato(s) profissional(is) obreiro(s). ${ }^{36}$
\end{abstract}

Mas não é possível inferir das normas mencionadas a exigência que veio a ser posta.

A Convenção n. 11 assegura o direito de sindicalização aos trabalhadores da agricultura, no que é seguida pela Convenção n. 141. Nenhuma das duas trata, contudo, de dispensa coletiva. Tampouco o faz a Convenção n. 87, ainda que se lhe deva reconhecer um papel central no campo da liberdade sindical, a ponto de figurar no rol das chamadas convenções fundamentais. ${ }^{37} \mathrm{~A}$ Convenção n. 98 proscreve práticas antissindicais, mas nada diz da necessidade de negociação antes de dispensa coletiva de empregados, necessidade que não decorre da previsão genérica de seu art. $4^{\circ}$, em que apenas se preconiza a adoção de

mesures appropriées... pour encourager et promouvoir le développement et l'utilisation les plus larges de procédures de négociation volontaire de conventions collectives entre

36 TST - SDC, Proc. n. 309/2009-000-15-00.4, Rel. Min. Mauricio Godinho Delgado, julg. em 10.8.2009, p. 30.

37 Cf. TREBILCOCK. A. Déclaration de l'OIT relative aux principes et droits fondamentaux au travail et son suivi. In: ODERO, A. Les normes internationales du travail. Genève: Organisation Internationale du Travail, 2001. p. 17-25. p. 19. 
les employeurs et les organisations d'employeurs d'une part, et les organisations de travailleurs d'autre part, en vue de régler par ce moyen les conditions d'emploi.

Já a Convenção n. 135 cuida da representação dos trabalhadores na empresa e cogita de medidas de proteção contra a dispensa dos representantes, não de providências a serem adotadas antes de dispensa coletiva.

Por fim, a Convenção n. 151 tem por objeto a organização sindical no âmbito da função pública. Busca favorecer a participação dos trabalhadores na definição das condições que lhe serão aplicáveis, é certo, ${ }^{38}$ mas não impõe a negociação sindical como requisito para a validade de dispensa coletiva.

Enfim, de nenhuma das normas internacionais mencionadas decorre a obrigação de negociar coletivamente antes de dispensar grande número de empregados. A importância que se reconhece à negociação coletiva e o propósito de a favorecer e de a estimular não levam a tornar obrigatória participação do sindicato nas dispensas coletivas. Não há, portanto, respaldo normativo, no plano do direito positivo ou por recepção do direito internacional, para a exigência que a jurisprudência veio a criar.

\section{Indeterminação do conceito}

Outro ponto importante no exame da legitimidade da exigência de negociação sindical para a dispensa coletiva de empregados envolve o próprio conceito. A jurisprudência criou a obrigação, sem definir a sua hipótese de incidência. Em outros termos, não se sabe, com algum grau de previsibilidade minimamente aceitável, quando há ou não a obrigação de negociar a dispensa.

No Direito Comparado, há os mais variados critérios, quantitativa e qualitativamente. Em alguns sistemas, o número de empregados não é um dado relevante. Importa o motivo das dispensas. É o caso da Ley Federal del Trabajo do México. ${ }^{39}$ Em outros sistemas jurídicos, ao contrário, não basta o motivo. O número de empregados

38 Cf. art. 7: "Des mesures appropriées aux conditions nationales doivent, si nécessaire, être prises pour encourager et promouvoir le développement et l'utilisation les plus larges de procédures permettant la négociation des conditions d'emploi entre les autorités publiques intéressées et les organisations d'agents publics, ou de toute autre méthode permettant aux représentants des agents publics de participer à la détermination desdites conditions".

39 O legislador mexicano considera coletiva a dispensa provocada pelas seguintes circunstâncias: "I. La fuerza mayor o el caso fortuito no imputable al patrón, o su incapacidad física o mental o su muerte, que produzca como consecuencia necesaria, inmediata y directa, la terminación de los trabajos; II. La incosteabilidad notoria y manifiesta de la explotación; III. El agotamiento de la materia objeto de una industria extractiva; IV. Los casos del artículo 38; y V. El concurso o la quiebra legalmente declarado, si la autoridad competente o los acreedores resuelven el cierre definitivo de la empresa o la reducción definitiva de sus trabajos." (art. 434). 
atingidos também é determinante. É o caso de Portugal, cujo Código do Trabalho assim define a dispensa coletiva: "Considera-se despedimento colectivo a cessação de contratos de trabalho promovida pelo empregador e operada simultânea ou sucessivamente no período de três meses, abrangendo, pelo menos, dois ou cinco trabalhadores, conforme se trate, respectivamente, de microempresa ou de pequena empresa, por um lado, ou de média ou grande empresa, por outro, sempre que aquela ocorrência se fundamente em encerramento de uma ou várias secções ou estrutura equivalente ou redução do número de trabalhadores determinada por motivos de mercado, estruturais ou tecnológicos" ${ }^{40} \mathrm{E}$ há ainda países em que o importante é o número de empregados dispensados em determinado período de tempo, independentemente do motivo, caso da Alemanha. ${ }^{41}$

Mesmo nos países em que se conjugam motivos com número de empregados, o parâmetro de quantificação oscila. Ora se indica número mínimo de empregados para que se qualifique como coletiva a dispensa, como é o caso já mencionado de Portugal; ora se estabelece apenas um percentual sobre o número total de empregados, caso da Colômbia; ${ }^{42}$ ora se conjugam percentuais com número de empregados, como na Espanha ${ }^{43}$ e na Alemanha. ${ }^{44}$

40 $\quad$ Art. $359^{\circ}$, n. 1.

41 FISCHER, Martin; MILDE, Siegurd. Employing Staff in Germany - Outline of German Labour Law. London: German-British Chamber of Industry \& Commerce, 2005. p. 42-43. Cf. § 17 da Lei de Proteção Contra Dispensa (Kündigungsschutzgesetz - KüSchG). Versão em inglês disponível em: $<$ http://www.mayrarbeitsrecht.de/wp-content/uploads/2016/05/Protection-Against-Unfair-Dismissal-Act.pdf $>$. Acesso em: 7 ago. 2016).

42 Art. 67, n. 4, da Lei n. 50, de 1990: "El Ministerio de Trabajo y Seguridad Social no podrá calificar un despido como colectivo sino cuando el mismo afecte en un período de seis (6) meses a un número de trabajadores equivalente al treinta por ciento $(30 \%)$ del total de los vinculados con contrato de trabajo al empleador, en aquellas empresas que tengan un número superior a diez (10) e inferior a cincuenta (50); al veinte por ciento $(20 \%)$ en las que tengan un número de trabajadores superior a cincuenta (50) e inferior a cien (100); al quince por ciento (15\%) en las que tengan un número de trabajadores superior a cien (100) e inferior a doscientos (200); al nueve por ciento $(9 \%)$ en las que tengan un número de trabajadores superior a doscientos (200) e inferior a quinientos (500); al siete por ciento (7\%) en las que tengan un número de trabajadores superior a quinientos e inferior a mil (1.000) y, al cinco por ciento (5\%) en las empresas que tengan un total de trabajadores superior a mil (1.000)."

43 Art. 51 do Estatuto de los Trabajadores: "Artículo 51. Despido colectivo. 1. A efectos de lo dispuesto en la presente Ley se entenderá por despido colectivo la extinción de contratos de trabajo fundada en causas económicas, técnicas, organizativas o de producción cuando, en un período de noventa días, la extinción afecte al menos a: a) Diez trabajadores, en las empresas que ocupen menos de cien trabajadores. b) El 10 por ciento del número de trabajadores de la empresa en aquéllas que ocupen entre cien y trescientos trabajadores. c) Treinta trabajadores en las empresas que ocupen más de trescientos trabajadores".

44 "The employer shall notify the Agency for Employment within 30 calendar days prior to dismissing 1. more than 5 employees in establishments with regularly more than 20 and fewer than 60 employees, 2. 10 per cent of the regularly employed employees or more than 25 employees in establishments with at least 60 and fewer than 500 employees, 3. at least 30 employees in establishments with regularly at least 500 employees.”. (Kündigungsschutzgesetz - KüSchG). Disponível em: <http://www.mayr-arbeitsrecht.de/wpcontent/uploads/2016/05/Protection-Against-Unfair-Dismissal-Act.pdf $>$. Acesso em: 7 ago. 2016. p. 6. 
Pode-se adotar qualquer critério. Cada um deles tem vantagens e desvantagens. O que não se concebe é a imposição de certa obrigação (negociar com o sindicato) a partir de um conceito (dispensa coletiva) mal definido ou, pior ainda, completamente não definido, como ocorre no presente caso. ${ }^{45}$ Abre-se espaço, com essa prática, para enorme insegurança jurídica, não sabendo as pessoas se e quando devem adotar determinado comportamento ou não. É o que se chama de concept flou, na expressão francesa, ${ }^{46}$ algo que atrai a severa crítica da doutrina, verbis: "l'indétermination d'une notion juridique est bien plus grave lorsque la construction d'une prévision juridique est rendue aléatoire, qu'il s'agisse d'un comportement à adopter ou d'un acte à conclure". ${ }^{47}$ Ao fim e ao cabo, transfere-se para a jurisprudência papel que não é propriamente o seu, de estabelecimento, de maneira casuística, do conceito. Passam os tribunais a ter de lidar com a ausência de parâmetros minimamente claros. ${ }^{48} \mathrm{Na}$ Itália, no período antecedente à Lei n. 223/1991, a doutrina chamava atenção para o fato de que a regulamentação “di origine giurisprudenziale, per la sua natura incerta e variabile, non poteva surrogare fonti legislative o collettive dotate di efficacia generale. Di qui l'esigenza di una normativa legale idonea a regolamentare la materia". ${ }^{49}$

Mais ainda, estabelecer heteronomamente exigência de negociação sindical em caso de dispensa coletiva, sem definir, todavia, o conceito, desconsidera o

45 Não por acaso, as propostas legislativas para regulamentação da matéria quase sempre começam pela definição do conceito de dispensa coletiva. É o caso, por exemplo, do Projeto de Lei n. 1.826/2015, em tramitação na Câmara dos Deputados, que trata da "requalificação profissional obrigatória em situações de dispensa em massa" e pretende inserir dispositivo com o seguinte teor na CLT: "Art. 486-A. Nos casos de dispensa sem justa causa de número igual ou superior a $10 \%$ (dez por cento) dos empregados, as empresas com mais de 100 (cem) empregados fornecerão ao trabalhador dispensado condições para sua requalificação profissional, visando a relocação na empresa ou reinserção no mercado de trabalho. Parágrafo único. No cômputo do número de trabalhadores dispensados, serão consideradas todas as dispensas realizadas no período de noventa dias". Não discrepa o Projeto de Lei n. 5.232/2009, cujos dois primeiros dispositivos estatuem: "Art. $1^{\circ} \mathrm{A}$ despedida coletiva, dispensa coletiva, demissões coletivas ou em massa por qualquer motivo será regulada pela presente lei. Art. $2^{\circ}$. Para os efeitos desta lei, é considerada despedida coletiva, dispensa coletiva, demissões coletivas ou em massa, a demissão de mais de $5 \%$ (cinco per cento) do quadro de funcionários das empresas públicas, das empresas privadas ou das empresas de economia mista que tenham mais de 100 (cem) funcionários, dentro do período de um ano". Podem ser citados também, sempre no mesmo sentido, os Projetos de Lei ns. 6.356/2005 e 5.353/2009.

46 PIAZZON, Thomas. La sécurité juridique. Paris: Defrénois, 2009. t. 35. (Collection: Doctorat \& Notariat). n. 127 , p. 226 e segs.

47 PIAZZON, Thomas. La sécurité juridique ... cit., n. 127, p. 229.

48 O Tribunal Superior do Trabalho certa feita registrou: “....inexistindo um conceito de dispensa coletiva em nossa legislação, além de a lei não estabelecer um percentual que sirva de parâmetro para a sua caracterização, esta Corte tem considerado que, afora o aspecto quantitativo, pertinente ao número de empregados desligados, deve ser levada em conta a repercussão econômica, social, política e assistencial que a dispensa possa ter acarretado." (TST - SDC, RO n. 60900-44.2012.5.13.0000, Rel. Dora Maria da Costa, julg. em 14.12.2015 in DEJT de 19.2.2016).

49 GHERA, Edoardo; GARILli, Alessandro; GAROFALO, Domenico. Diritto del lavoro. Torino: G. Giappichelli, 2013. p. 569. 
limite do art. $5^{\circ}$, inciso II, da Constituição. O princípio da legalidade na imposição de obrigações - postulado basilar na ideia de Estado de Direito - repele os concepts flous e reclama uma densificação mínima do conceito posto pela lei, ${ }^{50}$ que se traduz no divieto di indeterminatezza mencionado pela doutrina italiana. ${ }^{51}$ Quando a exigência é desrespeitada, incorre-se naquilo que no direito norte-americano se chama de void for vagueness ou unconstitutional uncertainty, configurada sempre que, nas palavras da Suprema Corte dos Estados Unidos, a norma legal "fails to provide a person of ordinary intelligence fair notice of what is prohibited, or is so standardless that it authorizes or encourages seriously discriminatory enforcement". ${ }^{52}$ Consoante a máxima romana, ubi jus incertum ibi jus nullum.

Ainda que certa margem de avaliação, de ponderação e de integração exista em toda norma legal - não se pretende afirmar o contrário e supor norma cuja aplicação seja feita de maneira mecânica, sem o contributo do julgador ${ }^{53}$-, não se pode levar a extremos a imprecisão. Não se imagina, por exemplo, punir-se a condução de veículo por motorista embriagado sem definição, todavia, do conceito de embriaguez. Como assentou a Corte Constitucional italiana - embora o tenha feito em matéria penal, campo em que o tema adquire particular sensibilidade, mas em termos extensíveis a outros domínios - a exigência de respeito à legalidade reclama da norma uma "descrizione intellegibile della fattispecie astratta". ${ }^{54}$

50 Cf. CAVALCANTI, Franciso de Queiroz Bezerra. A reserva de densificação normativa da lei para preservação do princípio da legalidade. In: BRANDÃO, Cláudio; CAVALCANTI, Francisco; ADEODATO, João Maurício. (Coord.). Princípio da legalidade: da dogmática jurídica à teoria do direito. Rio de Janeiro: Forense, 2009. p. 221 e segs.

51 CRISAFULLI, Vezio; PALADIN, Livio. Commentario breve alla Costituzione. Padova: CEDAM, 1990. p. 185 .

52 United States v. Williams (553 U.S. 285). Sobre o tema, em doutrina, LOCKWOOD, Cristina D. Defining indefiniteness: suggested revisions to the void for vagueness doctrine. Cardozo Public Law, Policy \& Ethics Journal, New York, v. 8, n. 2, Spring 2010. p. 255 e segs.

53 “...ogni norma, in quanto definizione di fattispecie astratte, pressuppone...un margine di indeterminatezza nell'individuazione dei comportamenti concreti da sussumere..." (CRISAFULLI, Vezio; PALADIN, Livio. Commentario breve alla Costituzione ... cit., p. 185).

54 Com a decisão (Sentença n. 96/1981), a Corte declarou a inconstitucionalidade do delito de plagio, tipificado no art. 603 do Código Penal, nos seguintes termos: "Chiunque sottopone una persona al proprio potere, in modo da ridurla in totale stato di soggezione, è punito con la reclusione da cinque a quindici anni”. A súmula dos fundamentos do julgado está no seu item 16, verbis: "L'esame dettagliato delle varie e contrastanti interpretazioni date all'art. 603 del codice penale nella dottrina e nella giurisprudenza mostra chiaramente l'imprecisione e l'indeterminatezza della norma, l'impossibilità di attribuire ad essa un contenuto oggettivo, coerente e razionale e pertanto l'assoluta arbitrarietà della sua concreta applicazione. Giustamente essa è stata paragonata ad una mina vagante nel nostro ordinamento, potendo essere applicata a qualsiasi fatto che implichi dipendenza psichica di un essere umano da un altro essere umano e mancando qualsiasi sicuro parametro per accertarne l'intensità. L'art. 603 del c.p., in quanto contrasta con il principio di tassatività della fattispecie contenuto nella riserva assoluta di legge in materia penale, consacrato nell'art. 25 della Costituzione, deve pertanto ritenersi costituzionalmente illegittimo". 
Deixar de lado a exigência de determinação do comando normativo seria, em verdade, o mesmo que transformar em lei o que lei não é, pois, "although it is impossible to precisely define all human conduct which is restricted by legislation, to make laws so vague that they will encompass every conceivable activity, is actually to make no law at all". ${ }^{55} \mathrm{E}$, como expressou Carnelutti, de maneira eloquente, "fin che si tratta di interpretare un verso della Divina Commedia il dubbio non fa male a nessuno, ma quando abbiamo da fare, invece, con un articolo del codice penale, se non viene eliminato, la macchina non funziona". ${ }^{56}$

\section{Aspectos a considerar}

A despeito da imprecisão apontada e de suas graves consequências do ponto de vista da validade da obrigação imposta, a exigência formulada pela jurisprudência força a necessidade de tentar-se alguma delimitação do conceito de dispensa coletiva. $\mathrm{Na}$ falta de previsão legal, pode-se tentar estabelecê-lo por exclusão, para dizer que é coletiva a dispensa que não se reveste de natureza individual, ou seja, aquela que não atinge um trabalhador, mas vários, por motivos que não lhes sejam pessoalmente imputáveis. Como posto pela Diretiva n. 98/59 da União Europeia, coletiva é a dispensa cujos motivos não sejam "inerentes à pessoa dos trabalhadores". ${ }^{57}$ Não é de considerar coletiva, portanto, a dispensa que, embora atinja vários empregados, esteja relacionada com a conduta individual deles na empresa. Por exemplo, identificado um grupo de trabalhadores com envolvimento em fraudes, a dispensa de todos, por justa causa, não é dispensa coletiva. Tal como se fala em ação individual plúrima, para indicar a ação que não é coletiva, mesmo envolvendo vários autores, é cabível falar, mutatis mutandis, em dispensa individual plúrima no caso da dispensa sem natureza coletiva de uma pluralidade de empregados.

A jurisprudência e a doutrina adicionam também mais dois elementos para a caracterização da dispensa como coletiva, a saber, a) elemento único na motivação ${ }^{58} \mathrm{e}$

55 Comentários em HERMAN, Jay R. Constitutional law - Void-for-Vagueness - United States v. Vuitch, 305 F. Supp. 1032 (D.C. Cir. 1969). Suffolk University Law Review, Boston, v. 4, n. 3, p. 920-929, Spring 1970. p. 921.

56 CARNELUTTI, Francesco. Metodologia del diritto. Padova: CEDAM, 1990. p. 49. Il va de soi que o espirituoso comentário não deve ser entendido como pertinente apenas ao Direito Penal, senão que válido igualmente para qualquer norma jurídica.

57 Art. 1, n. 1, alínea a).

58 “3. A descaracterização da hipótese de demissão coletiva, no caso vertente, emerge já do seu aspecto causal, que constitui o núcleo do conceito, por se tratar de premissa básica e constante na sua formulação, segundo as normas de direito internacional e direito comparado. Não se verifica aqui a existência de fato único, seja ele de ordem econômica, tecnológica ou estrutural, alheio à pessoa do empregado, que possa moldar o caso à hipótese de demissão coletiva. Trata-se, na espécie, de dispensa plúrima. Recurso Ordinário a que se nega provimento." (TST - SDC, Proc. RO n. 147-67.2012.5.15.0000, Rel. Min. Maria de Assis Calsing, julg. em 15.4.2013 in DEJT de 19.4.2013). Na doutrina, com alusão ao motivo único ("même motif"), 
b) redução definitiva dos empregos ou não substituição dos trabalhadores dispensados. ${ }^{59}$ O primeiro elemento não deve ser considerado de maneira estrita. Se os contratos de trabalho são rescindidos pela cumulação de motivos econômicos e tecnológicos, nem por isso deixa de ser coletiva a dispensa.

O estabelecimento de um número mínimo de empregados atingidos ou de um percentual para dar-se coloração coletiva à dispensa é bastante difícil no contexto nacional, ante a completa falta de previsão legal. Dizer, com segurança, que não é coletiva a dispensa por motivo econômico de 30 empregados num universo total de 200, por exemplo, não é possível. Será muito mais surpreendente chamar de coletiva, porém, a dispensa de 2 empregados, num universo de 100, ainda que o contrato de ambos haja sido rescindido pelo mesmo motivo, a redução da atividade da empresa, sem que outros trabalhadores tenham sido contratados para os substituir. A incerteza predomina e o casuísmo, com as suas indesejáveis discrepâncias arbitrárias, nem sempre compreensíveis ou aceitáveis, deve prevalecer.

Sem embargo da impossibilidade de limitação quantitativa antes mencionada, também se afigura problemático impor a negociação qualquer que seja o tipo de empresa e o número de empregados envolvidos. Ainda que ontologicamente deva ser vista como coletiva a dispensa de 3 empregados de uma padaria que antes contava com 6 trabalhadores, em decorrência de queda abrupta de receitas, provocada pela mudança no mercado local, soa aberrante exigir-se que seja precedida de discussão sindical. No Direito Comparado a dimensão da empresa é fator sempre levado em conta para estabelecer a exigência, ${ }^{60}$ tal como nos projetos de lei em tramitação no Congresso Nacional. ${ }^{61}$ Há um piso abaixo do qual a providência, seja qual for a natureza da dispensa, não se aplica, o que, aliás, já se vê no direito positivo, embora em outros campos. ${ }^{62}$

COUTURIER, Gérard. Droit du travail. Les relations individuelles de travail. 2e édition mise à jour, Paris: Presses universitaires de France, 1993. n. 150, p. 270.

59 “...dois traços caracterizam a dispensa coletiva, permitindo distingui-la da dispensa plúrima. São: a - a peculiaridade da causa; b - a redução definitiva do quadro do pessoal." (GOMES, Orlando. Dispensa coletiva na reestruturação da empresa: aspectos jurídicos do desemprego tecnológico. Revista LTr, São Paulo, ano 38, n. 7, jul. 1974.).

60 Cf. CARVALHO, Catarina de Oliveira. Da dimensão da empresa no direito do trabalho: consequências práticas da dimensão da empresa na configuração das relações laborais individuais e colectivas. Coimbra: Coimbra Editora, 2011. p. 375 e segs.

61 Cf. nota 42 , acima.

62 Cf. art. 74, $\S 2^{\circ}$, da CLT, e Lei Complementar n. 123, art. 51, com indicação de formalidades trabalhistas não aplicáveis às microempresas e às empresas de pequeno porte. 
10. Consequências do descumprimento da obrigação de negociar

Se o próprio conceito de dispensa coletiva não está definido, não surpreende que a sanção para o descumprimento da obrigação tampouco haja sido precisada. A incompletude na regra posta pela jurisprudência abrange tanto previsão quanto estatuição. Impossível, no entanto, deixar de formular a indagação: proibida a dispensa coletiva não precedida de negociação sindical, qual a consequência para a violação da regra, ou seja, qual o desdobramento jurídico que se segue? Afinal, a sanção para o descumprimento de uma norma jurídica pode variar e de fato varia, conforme os conhecidos modelos da lex perfecta, lex minus quam perfecta e lex imperfecta, ${ }^{63}$ sem prejuízo de certa combinação entre eles. ${ }^{64}$

Como não há disciplina legal da matéria, a jurisprudência refere alternativas distintas e opostas. Menciona tanto a reintegração dos dispensados ${ }^{65}$ como a inexistência de tal possibilidade, com mero pagamento de indenização. ${ }^{66}$ Tem predominado a última alternativa, por ser aquela referendada pelo Tribunal Superior do Trabalho. ${ }^{67}$ Mas hoje já se vai além, para deferir indenização adicional, sob a forma de dano moral coletivo, ${ }^{68}$

63 RÁO, Vicente. O direito e a vida dos direitos. 4. ed. anotada e atual. por Ovídio Rocha Barros Sandoval. São Paulo: RT, 1997. v. 1. n. 215, p. 297/298. Para exame doutrinário do tema, sob a perspectiva do Direito Romano, cf. KLABIN, Aracy Augusta Leme. Observações sobre a sanção (sanctio) das leis em direito romano. Revista da Faculdade de Direito da Universidade de São Paulo, São Paulo, v. 91, p. 37-43, jan./ dez. 1996. p. 37 e segs.

${ }^{64}$ Quando à privação de efeito ao ato praticado em contraste com a lei se cumula multa, há combinação de lex perfecta com lex minus quam perfecta, o que levou os juristas medievais a uma quarta categoria, a da lex maius quam perfecta. (ASCENSÃO, José de Oliveira. O direito, introdução e teoria geral: uma perspectiva luso-brasileira. 6. ed. rev. Coimbra: Livraria Almedina, 1991. n. 54, p. 108).

65 "5. Declaro nula a demissão em massa, com fundamento nos artigos (art. $1^{\circ}$, III e IV, art. $5^{\circ}$, XIV, art. $7^{\circ}, \mathrm{XXVI}, 8^{\circ}$ III e VI, CF) tendo em vista a inobservância do procedimento de negociação coletiva e do direito de informação, sendo que deverão ser revistas para observar o procedimento adequado." (TRT $-2^{\mathrm{a}}$ Reg., SDC, Proc. n. 20281200800002001, Rel. Ivani Contini Bramante, Ac. n. 00002/2009-0, julg. em 22.12.2008).

${ }^{66}$ No acórdão do TRT da $15^{\text {a }}$ Região consta: “...declaro: a) a abusividade do procedimento das suscitadas ao praticar a dispensa coletiva, sem nenhuma negociação coletiva prévia com as entidades sindicais, nem instituição de programa de demissão voluntária incentivada; b) a inexistência de garantia de emprego ou de estabilidade que justifique a reintegração, ressalvados os casos de estabilidade provisória previstos em lei ou em normas coletivas, que poderão ser objeto de dissídios individuais; c) o direito de cada empregado demitido a uma compensação financeira de dois valores correspondentes a um mês de aviso prévio, até o limite de sete mil reais...” (TRT $15^{\text {a }}$ Reg., SDC, Proc. n. 00309-2009-000-15-00-4 DC, Rel. José Antonio Pancotti, Ac. 00333/09 in DEJT de 30.3.2009).

67 No acórdão do TST consta: “...declaro: a) a abusividade do procedimento das suscitadas ao praticar a dispensa coletiva, sem nenhuma negociação coletiva prévia com as entidades sindicais, nem instituição de programa de demissão voluntária incentivada; b) a inexistência de garantia de emprego ou de estabilidade que justifique a reintegração, ressalvados os casos de estabilidade provisória previstos em lei ou em normas coletivas, que poderão ser objeto dissídios individuais..." (TST - SDC, Proc. n. 309/2009-000-15-00.4, Rel. Min. Mauricio Godinho Delgado, julg. em 10.8.2009 in DJ de 17.8.2009).

68 "Recurso de revista. Dispensa em massa de trabalhadores. Ausência de negociação prévia. Indenização por dano moral coletivo. Dissídio coletivo posterior. O que determina o dano moral coletivo é a conduta ilícita 
prática que envolve, em grande medida, importação, para o direito nacional, dos punitive damages do direito do common law. ${ }^{69}$ A condenação, no particular, costuma ser genérica, sem indicação clara do prejuízo ou dos elementos que justificam o montante arbitrado, com mera utilização de fórmulas abstratas, como a natureza do direito violado, o porte da empresa e a conduta verificada.

\section{Conclusão}

A falta de delimitação do conceito de dispensa coletiva faz com que a exigência de negociação sindical antecedente, criada pela jurisprudência, suscite sérios problemas teóricos e práticos, inclusive em torno da legitimidade constitucional da obrigação. Há que considerar, ademais, que, se alguma dispensa deve ser melhor disciplinada no direito brasileiro, com limitação da ampla liberdade atualmente conferida ao empregador, é a individual, antes da coletiva. O custo econômico inerente à dispensa de vários empregados, os impactos sobre a continuidade do negócio e a perda de informações na empresa, além de outras consequências desfavoráveis para o empregador, fazem com que sua implementação costume ser, salvo em situações excepcionais, mais contidas. Se é fácil imaginar uma dispensa individual gratuita ou realizada de maneira precipitada, sem real necessidade - o que é sempre indesejável -, é muito mais difícil que o mesmo ocorra quando se trata de dispensa coletiva, subjacente à qual costuma haver razões econômicas, estruturais ou tecnológicas.

São Paulo, agosto de 2016.

\section{Referências}

AMORIM, Daniela. Desemprego sobe e renda volta ao nível de 2013. O Estado de S. Paulo, São Paulo, 30 jul. 2016. Caderno Economia, p. B6.

do empregador, que atinge a esfera moral da sociedade, como no caso em exame, em que a empresa procede a dispensa em massa dos trabalhadores, violando o princípio constitucional do trabalho, que conceitua também o princípio da dignidade do trabalhador. A reparação é devida com o fim de restituir o patrimônio imaterial em face do ato ilícito em relação a grupo de trabalhadores, no importe de $\mathrm{R} \$ 50.000,00$, com o fim de atribuir caráter pedagógico à condenação, levando em consideração que, em dissídio coletivo o grupo de trabalhadores teve garantida a nulidade do ato, tendo a empresa realizado acordo que possibilitou amenizar a conduta ilícita já perpetrada. Recurso de revista conhecido e provido." (TST - 6 ${ }^{\mathrm{a}}$ T., Proc. RR - 980084.2009.5.02.0251, Rel. Min. Aloysio Corrêa da Veiga, julg. em 26.9.2012 in DEJT 28.9.2012).

69 Para um excelente e profundo exame do tema dos punitive damages, em uma das melhores obras da bibliografia nacional, cf. HIGA, Flávio da Costa. Responsabilidade civil punitive: os "punitive damages" no direito brasileiro. Rio de Janeiro: Lumen Juris, 2016. passim. 
ASCENSÃO, José de Oliveira. O direito, introdução e teoria geral: uma perspectiva luso-brasileira. 6. ed. rev. Coimbra: Livraria Almedina, 1991.

ÁVILA, Humberto. "Neoconstitucionalismo": entre a "ciência do direito" e o direito da ciência". Revista Eletrônica de Direito do Estado (REDE), Salvador, n. 17, p. 1-19, jan./mar. 2009.

BOBBIO, Norberto. Teoria dell'ordinamento giuridico. Torino: G. Giappichelli, 1960.

CAMERLYNCK, G. H., Traité de droit du travail. Contrat de travail. Paris: Dalloz, 1968.

CARNELUTTI, Francesco. Metodologia del diritto. Padova: CEDAM, 1990.

CARVALHO, Catarina de Oliveira. Da dimensão da empresa no direito do trabalho: consequências práticas da dimensão da empresa na configuração das relações laborais individuais e colectivas. Coimbra: Coimbra Editora, 2011.

CAVALCANTI, Franciso de Queiroz Bezerra. A reserva de densificação normativa da lei para preservação do princípio da legalidade. In: BRANDÃO, Cláudio; CAVALCANTI, Francisco; ADEODATO, João Maurício. (Coord.). Princípio da legalidade: da dogmática jurídica à teoria do direito. Rio de Janeiro: Forense, 2009.

CORTÊS, António. Jurisprudência dos princípios: ensaio sobre os fundamentos da decisão jurisdicional. Lisboa: Universidade Católica Editora, 2010.

COUTURIER, Gérard. Droit du travail. Les relations individuelles de travail. 2e édition mise à jour, Paris: Presses universitaires de France, 1993.

CRISAFULLI, Vezio; PALADIN, Livio. Commentario breve alla Costituzione. Padova: CEDAM, 1990.

DU PASQUIER, Claude. Introduction à la théorie générale et à la philosophie du droit. 3. ed., mise a jour et augm. Neuchatel: Delachaux \& Niestlé, 1948.

ESPINOLA, Eduardo; ESPINOLA FILHO, Eduardo. A lei de introdução ao código civil brasileiro. Rio de Janeiro: Freitas Bastos, 1943. v. 1.

FERNANDES, Adriana; DE CHIARA, Márcia. Varejo fechou 375 lojas por dia este ano. O Estado de S. Paulo, São Paulo, 3 ago. 2016. Caderno Economia, p. B6.

FISCHER, Martin; MILDE, Siegurd. Employing Staff in Germany - Outline of German Labour Law. London: German-British Chamber of Industry \& Commerce, 2005.

GHERA, Edoardo; GARILLI, Alessandro; GAROFALO, Domenico. Diritto del lavoro. Torino: G. Giappichelli, 2013.

GOMES, Orlando. Dispensa coletiva na reestruturação da empresa: aspectos jurídicos do desemprego tecnológico. Revista LTr, São Paulo, ano 38, n. 7, jul. 1974.

HERMAN, Jay R. Constitutional law - Void-for-Vagueness - United States v. Vuitch, 305 F. Supp. 1032 (D.C. Cir. 1969). Suffolk University Law Review, Boston, v. 4, n. 3, p. 920-929, Spring 1970. 
HIGA, Flávio da Costa. Responsabilidade civil punitive: os "punitive damages" no direito brasileiro. Rio de Janeiro: Lumen Juris, 2016.

JOSSERAND, Louis. De l'esprit des droits et de leur relativité. Théorie dite de l'abus des droits. Paris: Dalloz, 1939.

KLABIN, Aracy Augusta Leme. Observações sobre a sanção (sanctio) das leis em direito romano. Revista da Faculdade de Direito da Universidade de São Paulo, São Paulo, v. 91, p. 37-43, jan./ dez. 1996.

LA GRESSAYE, Jean Brethe de; LABORDE-LACOSTE, Marcel. Introduction générale a l'étude du droit. Paris: Sirey, 1947.

LOCKWOOD, Cristina D. Defining indefiniteness: suggested revisions to the void for vagueness doctrine. Cardozo Public Law, Policy \& Ethics Journal, New York, v. 8, n. 2, Spring 2010.

NOVAIS, Jorge Reis. A dignidade da pessoa humana. Dignidade e direitos fundamentais. Coimbra: Almedina, 2015. v. 1.

NOVAIS, Jorge Reis. A dignidade da pessoa humana. Dignidade e inconstitucionalidade. Coimbra: Almedina, 2016. v. 2.

PIAZZON, Thomas. La sécurité juridique. Paris: Defrénois, 2009. t. 35. (Collection: Doctorat \& Notariat).

RAMOS, Elival da Silva. Parâmetros dogmáticos do ativismo judicial em matéria constitucional. 2009. Tese (Professor Titular) - Faculdade de Direito, Universidade de São Paulo, São Paulo, 2009.

RÁO, Vicente. O direito e a vida dos direitos. 4. ed. anotada e atual. por Ovídio Rocha Barros Sandoval. São Paulo: RT, 1997. v. 1.

SCYBOZ, Georges; GILLIÉRON, Pierre-Robert; SCYBOZ, Pierre. Code civil suisse et Code des obligations: annotés. 7e éd. mise à jour. Lausanne: Payot, 2004.

SILVA, Cleide; ROCHA, André Ítalo. Mercedes-Benz anuncia demissões no ABC e metalúrgicos param produção. O Estado de S. Paulo, São Paulo, 5 ago. 2016. Caderno Economia, p. B10.

TENÓRIO, Oscar Acioli. Lei de introdução ao código civil brasileiro: decreto-lei n. 4.657, de 4 de setembro de 1942. Rio de Janeiro: Borsoi, 1955.

TREBILCOCK. A. Déclaration de l'OIT relative aux principes et droits fondamentaux au travail et son suivi. In: ODERO, A. Les normes internationales du travail. Genève: Organisation Internationale du Travail, 2001. p. 17-25. 